Journal of Advanced Research in Fluid Mechanics and Thermal Sciences

Journal homepage: www.akademiabaru.com/arfmts.html ISSN: 2289-7879

\title{
Experimental and Numerical Study for Estimation and Reduction of The Blind Spot in A Passenger Car
}

\author{
Thara Reshma I. V. ${ }^{1}$, Mohammad Zuber ${ }^{1}$, Shlok Gupta ${ }^{1}$, Akhil Agarwal ${ }^{1}$, Sharun Hegde ${ }^{1}$, Chethan K \\ $\mathrm{N}^{1, *}$ \\ Department of Aeronautical and Automobile Engineering, Manipal Institute of Technology, Manipal Academy of Higher Education, Manipal - \\ 576104, Karnataka, India
}

\section{ARTICLE INFO}

\section{Article history:}

Received 28 June 2021

Received in revised form 31 July 2021

Accepted 10 August 2021

Available online 18 September 2021

\section{Keywords:}

Blind Spot; B-Pillar Blind spot region; Accident Prevention; Wake survey; flow simulations; Computational Fluid Dynamics

\section{ABSTRACT}

The purpose of developing an automobile was to reduce human effort, travel faster, and cover longer distances. Cars were meant for transporting a small number of people from one point to another. In India, the four-wheeler segment has picked up over the years due to economic liberalization. The vehicles have been undergoing constant improvements. This may be either in the design or the final product. Also, the importance of aerodynamics is a crucial factor considered while designing a vehicle. This study focuses on improving the aerodynamics of the side-view mirror and reducing the blind spot region. The side mirror of Toyota Etios Liva was used in this study. Blind spots were first determined, and the mirror drag is analyzed experimentally in a wind tunnel and numerically using commercial software. The results show that the drag value of the new mirror was 0.449 compared to 0.634 of the original mirror. This work helps to reduce the blind spot region of the car considered for the study.

\section{Introduction}

An automobile was made to move goods and people from one location to the other. The first vehicle had a steam engine to propel it. Then Etienne Lenoir in the year 1860 used gas as fuel in the internal combustion engine. Later gasoline was used as a combustible substance [1,2]. Self-propelled vehicles have evolved over the years. Particularly in India, the purchase takes many factors into considerations namely brand image, price, marketing, comfort, performance, services, and many other such factors [3-5]. The year 1985 is important in Indian automobile history as it marks the sales of passenger vehicles crossing 100,000 [6,7]. The main criteria include price and efficiency (fuel) [8]. A car is particularly designed keeping in mind end users. Hence as time passes there are improvements in all categories [9]. Aluminum composites are used to make it lighter at the same time not compromising on strength [10-12]. The aerodynamics of the vehicle has been uplifted over the years by making the design more streamlined. This leads to a reduction in fuel consumption and

\footnotetext{
* Corresponding author.

E-mail address: chethan.kn@manipal.edu
}

https://doi.org/10.37934/arfmts.87.2.6681 
increased speed [13]. Hassan et al., [14] studied the importance of aerodynamic drag, finding the drag coefficient and improvement in designs to cut down the drag. Ramya et al., [15] analyzed two car models and found that the sports utility vehicle (SUV) is more streamlined in shape compared to the sedan model, and the use of a spoiler lessens the drag in both models. Bijlani et al., [16] conducted research experimentally and analytically on sedan and square back cars and found that sedan is more aerodynamic than the square back. Ghani [17] defined the parameters geometrically using NURBS (Non-uniform rotational B-spline). Mirrors are utilized to find out any vehicles approaching and any obstruction to the reference one. They are two side-view mirrors and a rearview mirror. Al-Obaidi and Otten [18] considered Perodua Myvi of 2011 model for computational fluid dynamics simulation from which it is clear that it owes to the rise of drag. Sotelo and Barriga [19] showed the use of a blind-spot detection system to help the driver overtake and warn him of the vehicles in the blind spot region. This system had about a 99\% perception rate. Al-Jafar [20] utilized electronic and ultrasonic sensors placed on the outer side of each side-view mirror, warning lights, and on the inner side of the mirrors, another sensor on the steering wheel to know the position of the front tires and an alarm. This system works in such a way that the sensor on the mirror detects the automobile in the blind spot and gives the driver an indication with the help of warning lights and alarms. Hirota et al., [21] forged two focal plane arrays with the integrated circuit in Nissan ASV-2. This is done to detect pedestrian with the help of infrared radiated from the body, it also prevents the car from going in that direction. Another system is a rearview camera and infrared sensors which warn the driver of any pedestrian in the blind spot. Some other attempts to reduce the blind spot include: blind spot mirror is also incorporated in the side mirror with a motor, power supply and defroster that ensures it works fine even in cold conditions, signals obtained from the electronic control unit are used to either bring it out or send it back in as per requirements [22]. Micro-controller and ultrasonic sensors are placed on the sides of the vehicle to detect vehicles coming near the reference one and gives an indication in the form of LED lights (side mirrors) and alarms [23]. Radar of $24 \mathrm{GHz}$ was used to determine the distance and speed of the car in the blind spot region [24]. CFD plays an important role in understanding the flow dynamics $[25,26]$. Previously several aerodynamic drag studies are performed using CFD techniques [27,28].

In this study, blind spots are first determined with the help of a rotating pole. Samples of five mirrors with different radii of curvature are taken, and tests are carried out to find out the most suitable one where the blind spot was the least. Then, the length after this is compared with the Automotive Research Association of India (ARAI) standards. Later it is fitted in the side view plastic cover, and its flow is analyzed in the Wind Tunnel testing facility. A CFD study was also carried out using ANSYS R-18. Results obtained reveal a reduction in drag of the new mirror compared to the old one.

\section{Methodology}

The current work deals with experimental and computational studies to detect and reduce blind spots in a four-wheeler. There are a series of experiments involved in this project. It starts with data collection using a rotating pole to identify the blind spot of an Etios Liva when used by 40 different people.

\subsection{Blind Spot Region Estimation}

Toyota Etios Liva 2011 model is considered for this study. The Etios Liva is the hatchback version of the Etios sedan, as shown in Figure 1. It is a front-engine, front-wheel-drive car that is assembled 
at the Bidadi Plant of Toyota in Karnataka. This vehicle is chosen because it is one of the top sellers in India's 'Entry-Level Hatchback' segment.

To develop an accurate testing rig we considered a circle of diameter $14 \mathrm{feet}$, which was large enough to accommodate three average-sized cars. Then we manufactured a pole equivalent to the height of the car with bright red and yellow stripes for visibility, as shown in Figure 1.

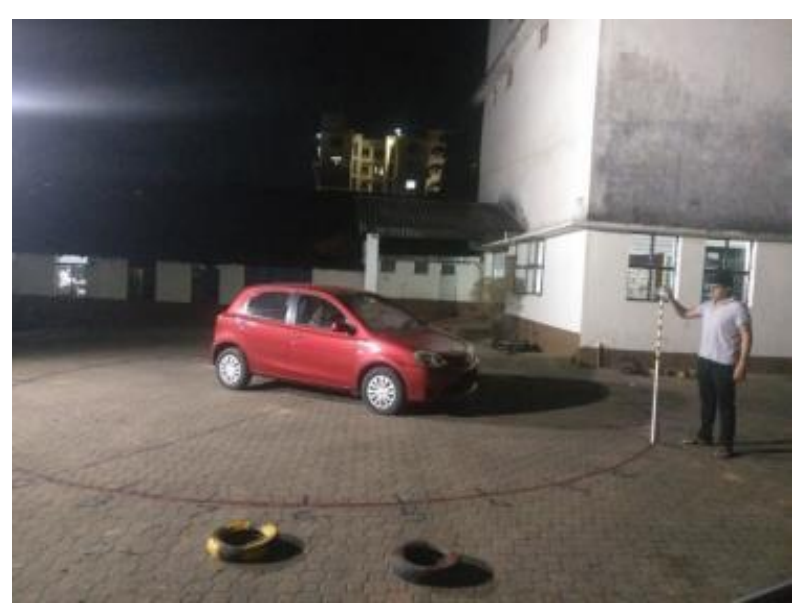

Fig. 1. An image taken during the blind spot estimation using the testing rig based on the concept of a rotating pole

The first step was sketching the seven feet radius circle on level ground. This was done using a blackboard-sized protractor and a thin rod. After that, the wheel positions on the ground were marked and the car was parked on them. Bright red and white colours were used for sketching and numbering for increased visibility. The first step of collecting data was to make sure each individual has adjusted the seat position, the steering alignment, fastened the seatbelt, aligned the center rearview mirror so that the entire rear windshield is visible, and align the two side-view mirrors so that the minimum portion of the car body is visible on it (but some portion should be visible for sure). After that, the pole was revolved around the marked circle around the car, and the driver had to point out whenever the pole was invisible from the front windshield, two front door windows, or on the three rear-view mirrors. The readings are taken from 40 people of various age groups, weights, and heights. Individuals are chosen with height ranging from $5^{\prime} 2^{\prime \prime}$ to $6^{\prime} 5^{\prime \prime}$, aged between 18 to 52 years and weighing between 50 to $92 \mathrm{~kg}$ to obtain a wide sample space for the analysis.

After the initial ten readings, the accuracy of the focused region of the circle was increased by increasing the number of divisions on it. The collected data is shown in Table 1. Along with the four blind-spot regions on a car which are due to its chassis structure, another region was plotted, which was identified as the blockage of view because of a co-passenger in the front seat. This blockage is usually dangerous while taking a right on ' $T$ ' roads. The graph represents the data collected in the experiment, as shown in Figure 2. Starting from the $5^{\circ} 30^{\prime}$ triangle, going clockwise, each triangle represents either a field of view or a blind spot. The following are a few blind spot regions-blind spot due to Driver side A-pillar, a field of view through the driver side door window, a blind spot due to Driver side B pillar, a field of view through the driver side's side-view mirror, a field of view through the center rear-view mirror, field of view through the passenger side's side-view mirror, blind spot due to Passenger side B pillar, blind spot due to the co-passenger in the front seat (dotted line), a field of view through the passenger side door window, blind spot due to passenger side A-pillar and field of view through the front windshield. 


\section{Table 1}

Flow data collected from the wind tunnel for the side view mirror

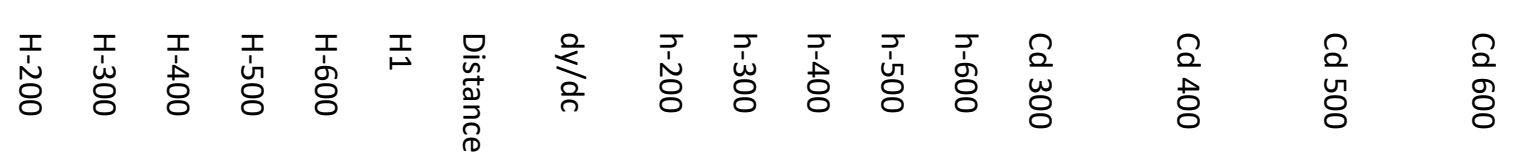

\begin{tabular}{|c|c|c|c|c|c|c|c|c|c|c|c|c|c|c|c|c|}
\hline 44 & 50 & 62 & 76 & 95 & 38 & 0 & 41.5 & 6 & 12 & 24 & 38 & 57 & -0.0488 & -0.0406 & -0.0393 & -0.0401 \\
\hline 44 & 50 & 62 & 76 & 95 & 38 & 3 & 38.5 & 6 & 12 & 24 & 38 & 57 & -0.0453 & -0.0377 & -0.0364 & -0.0372 \\
\hline 44 & 49 & 62 & 76 & 95 & 38 & 6 & 35.5 & 6 & 11 & 24 & 38 & 57 & -0.0342 & -0.0347 & -0.0336 & -0.0343 \\
\hline 44 & 49 & 62 & 76 & 95 & 38 & 9 & 32.5 & 6 & 11 & 24 & 38 & 57 & -0.0313 & -0.0318 & -0.0307 & -0.0314 \\
\hline 44 & 49 & 62 & 76 & 95 & 38 & 11.5 & 30 & 6 & 11 & 24 & 38 & 57 & -0.0289 & -0.0293 & -0.0284 & -0.029 \\
\hline 44 & 49 & 62 & 76 & 95 & 38 & 13.5 & 28 & 6 & 11 & 24 & 38 & 57 & -0.027 & -0.0274 & -0.0265 & -0.0271 \\
\hline 44 & 49 & 62 & 76 & 95 & 38 & 17 & 24.5 & 6 & 11 & 24 & 38 & 57 & -0.0236 & -0.024 & -0.0232 & -0.0237 \\
\hline 44 & 49 & 62 & 76 & 95 & 38 & 21 & 20.5 & 6 & 11 & 24 & 38 & 57 & -0.0197 & -0.0201 & -0.0194 & -0.0198 \\
\hline 44 & 49 & 62 & 76 & 95 & 38 & 24 & 17.5 & 6 & 11 & 24 & 38 & 57 & -0.0169 & -0.0171 & -0.0166 & -0.0169 \\
\hline 44 & 49 & 62 & 76 & 94 & 38 & 27 & 14.5 & 6 & 11 & 24 & 38 & 56 & -0.014 & -0.0142 & -0.0137 & -0.0134 \\
\hline 44 & 49 & 62 & 76 & 94 & 38 & 29.3 & 12.2 & 6 & 11 & 24 & 38 & 56 & -0.0117 & -0.0119 & -0.0115 & -0.0113 \\
\hline 44 & 49 & 62 & 76 & 94 & 38 & 32.5 & 9 & 6 & 11 & 24 & 38 & 56 & -0.0087 & -0.0088 & -0.0085 & -0.0083 \\
\hline 44 & 49 & 61 & 76 & 94 & 38 & 36.5 & 5 & 6 & 11 & 23 & 38 & 56 & -0.0048 & -0.0044 & -0.0047 & -0.0046 \\
\hline 44 & 49 & 59 & 75 & 94 & 38 & 38.5 & 3 & 6 & 11 & 21 & 37 & 56 & -0.0029 & -0.0021 & -0.0027 & -0.0028 \\
\hline 44 & 48 & 59 & 73 & 90 & 38 & 42 & 0 & 6 & 10 & 21 & 35 & 52 & 0 & 0 & 0 & 0 \\
\hline 44 & 48 & 58 & 68 & 85 & 38 & 45 & 3.5 & 6 & 10 & 20 & 30 & 47 & -0.0026 & -0.0021 & -0.0017 & -0.002 \\
\hline 44 & 48 & 55 & 66 & 80 & 38 & 48 & 6.5 & 6 & 10 & 17 & 28 & 42 & -0.0049 & -0.0022 & -0.0024 & -0.0025 \\
\hline 44 & 46 & 52 & 62 & 75 & 38 & 51 & 9.5 & 6 & 8 & 14 & 24 & 37 & -0.0034 & -0.0008 & -0.0015 & -0.0019 \\
\hline 43 & 45 & 49 & 57 & 67 & 38 & 54.5 & 13 & 5 & 7 & 11 & 19 & 29 & -0.0023 & 0.0019 & 0.0011 & 0.0008 \\
\hline 42 & 45 & 46 & 52 & 56 & 38 & 57 & 15.5 & 4 & 7 & 8 & 14 & 18 & -0.0027 & 0.0052 & 0.0046 & 0.0056 \\
\hline 41 & 44 & 43 & 46 & 45 & 38 & 60 & 18.5 & 3 & 6 & 5 & 8 & 7 & -0.00003 & 0.00871 & 0.00872 & 0.00923 \\
\hline 40 & 42 & 42 & 43 & 42 & 38 & 63 & 21.5 & 2 & 4 & 4 & 5 & 4 & 0.0064 & 0.0106 & 0.0108 & 0.0099 \\
\hline 40 & 41 & 42 & 42 & 41 & 38 & 66 & 24.5 & 2 & 3 & 4 & 4 & 3 & 0.0101 & 0.0121 & 0.0121 & 0.0105 \\
\hline 39 & 40 & 42 & 42 & 40 & 38 & 69 & 27.5 & 1 & 2 & 4 & 4 & 2 & 0.0134 & 0.0136 & 0.0135 & 0.0104 \\
\hline 39 & 40 & 42 & 42 & 40 & 38 & 71 & 29.5 & 1 & 2 & 4 & 4 & 2 & 0.0144 & 0.0146 & 0.0145 & 0.0112 \\
\hline
\end{tabular}




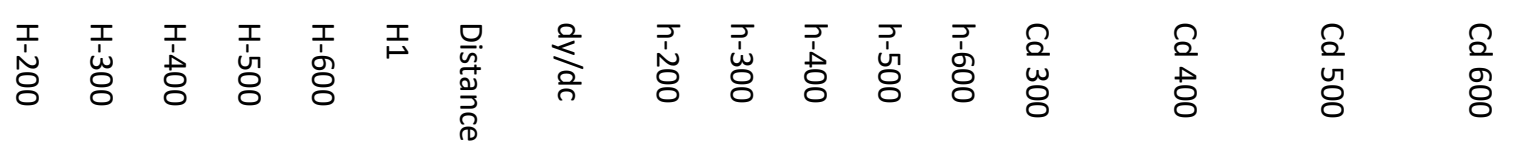

$\begin{array}{llllllllllllllllll}39 & 40 & 42 & 42 & 40 & 38 & 75 & 33.5 & 1 & 2 & 4 & 4 & 2 & 0.0163 & 0.0166 & 0.0165 & 0.0127 \\ 39 & 40 & 43 & 42 & 41 & 38 & 78 & 36.5 & 1 & 2 & 5 & 4 & 3 & 0.0178 & 0.0172 & 0.018 & 0.0157 \\ 39 & 40 & 43 & 42 & 41 & 38 & 81 & 39.5 & 1 & 2 & 5 & 4 & 3 & 0.0193 & 0.0186 & 0.0195 & 0.0169 \\ 40 & 39 & 43 & 43 & 42 & 38 & 84.5 & 43 & 2 & 1 & 5 & 5 & 4 & 0.0208 & 0.0203 & 0.0215 & 0.0198 \\ 41 & 42 & 42 & 42 & 40 & 38 & 86 & 44.5 & 3 & 4 & 4 & 4 & 2 & 0.0133 & 0.022 & 0.0219 & 0.0169 \\ & \end{array}$

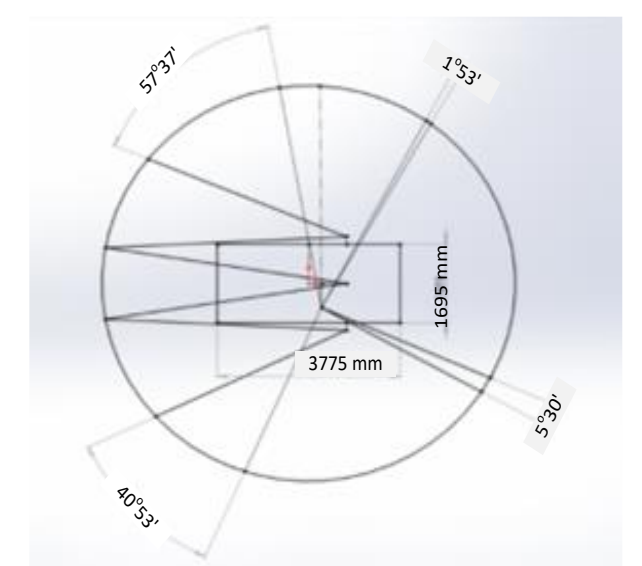

Fig. 2. Circle of vision of the original vehicle with blind-spot regions highlighted

Figure 3 shows a 5 -lane road using a 50 feet diameter circle with triangles representing blind-spot regions. It shows how the other top-selling vehicles in India could easily be in the blind spot region on the Etios Liva. Graph specifications are given as: lane width $=10 \mathrm{feet}$, circle radius $=25$ feet and number of lanes $=5$. Vehicles from top to bottom (see Figure 3 ) are Honda City $(4440 \times 1695 \mathrm{~mm})$, Maruti Alto 800 (3395 x 1515 mm), Toyota Etios Liva (3775 x 1695 mm), Bajaj Pulsar 180 (2035 x 765 $\mathrm{mm}$ ) and Maruti Swift Dzire (3995 x $1735 \mathrm{~mm}$ ), respectively. 


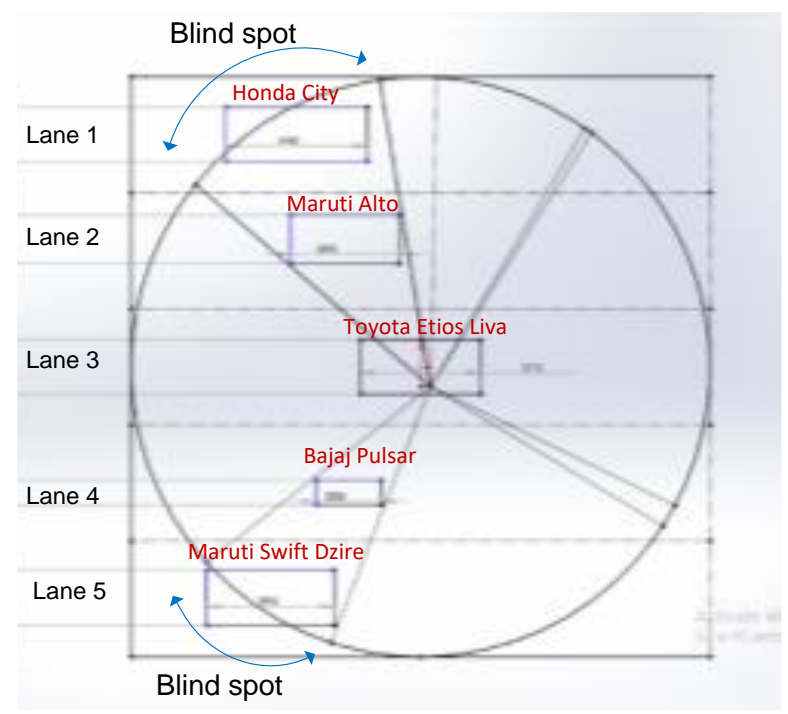

Fig. 3. Visual representation of the region covered by the blind spot on a five-lane. Highlighting the variety of vehicles that are hidden in the blind spot

The position of the side view mirror was moved horizontally on the vehicle to record any changes in the field of view through the side-view mirror, which revealed no substantial results. Changing the location of the side view mirror itself on the car would incur high costs due to changes in the manufacturing of the body panels. Therefore, this idea was discarded. Mirrors of different radii of curvature were tested, and readings were noted from 5 members of the initial 40. Two brackets are made, which can be attached to the existing side-view mirror to hold the test mirrors in place. Then the experiment, as mentioned in the first step, was performed again. It is found that a mirror with an inner radius of curvature of $444 \mathrm{~mm}$ and an outer radius of curvature of $407 \mathrm{~mm}$ was able to cover almost the whole blind spot region due to B pillars of the vehicle. Then new mirror is $445 \mathrm{~mm} / 365$ $\mathrm{mm}$ in radii.

Table 2

Final test mirror data

\begin{tabular}{|c|c|c|c|c|}
\hline Person number & B-Pillar in ${ }^{\circ} \mathrm{s}$ & Driver in ${ }^{\circ} \mathrm{s}$ & B-Pillar in ${ }^{\circ} \mathrm{s}$ & Passenger in ${ }^{\circ} \mathrm{S}$ \\
\hline 1 & 109.00 & 137.27 & 219.00 & 260.20 \\
\hline 2 & 110.00 & 137.27 & 219.00 & 261.00 \\
\hline 3 & 109.40 & 137.27 & 219.00 & 259.54 \\
\hline 4 & 108.80 & 137.27 & 219.00 & 260.50 \\
\hline 5 & 109.70 & 137.27 & 219.00 & 259.80 \\
\hline Average Values & 107.40 & 137.27 & 219.00 & 262.36 \\
\hline
\end{tabular}

A spherometer is an instrument for the precise measurement of the Radius of the curvature of a sphere or a curved surface. Originally, these instruments were primarily used by opticians to measure the curvature of the surface of a lens. The spherometer works on the principle of the micrometre screw. It consists of a metallic tripod framework supported on three fixed legs of equal lengths. A screw passes through the center of the tripod frame, parallel to the three legs. A large circular disc graduated with 100 equal parts is attached to the top of the screw. A small vertical scale known as the Pitch scale $(P)$ with the scale reading divided into millimetre is fixed at one end of the tripod frame. The average Radius was found to be $407.79 \mathrm{~mm}$. The detailed calculations are as shown 
The least Count of the Spherometer

$P=\frac{\mathrm{d}}{\mathrm{n}} m m$

If there are $\mathrm{N}$ divisions in the circular scale on the circumference of the disc, then.

Least Count $=\frac{\mathrm{P}}{\mathrm{N}} \mathrm{mm}=\frac{1}{100} \mathrm{~mm}=0.01 \mathrm{~mm}$

Spherometer Calculations:

$\mathrm{P}=\frac{\mathrm{d}}{\mathrm{n}} m m=1 \mathrm{~mm}$

Least count $=\frac{\mathrm{P}}{\mathrm{N}} m m=\frac{1}{100} \mathrm{~mm}=0.01 \mathrm{~mm}$

$\mathrm{L}=40 \mathrm{~mm}$

$R=\frac{L^{2}}{6 h}+\frac{h}{2}$

$h=(n \times P)+(X \times L C)$

Toyota View Side Mirror

Centre- $a=65,60$

$x=45,45$

$\mathrm{n}=0,0$

$\mathrm{h}=.45, .45$

$\mathrm{R}=592.81 \mathrm{~mm}$

Side-a $=60,65$

$x=50,55$

$\mathrm{n}=0,0$

$\mathrm{h}=.50, .55$

$\mathrm{R}=509.35 \mathrm{~mm}$

Average Radius $=551.08 \mathrm{~mm}$

Test Specimen 5 Side View Mirror

Centre- $a=99,94$

$x=59,61$

$\mathrm{n}=0,0$

$\mathrm{h}=.59, .61$

$\mathrm{R}=444.86 \mathrm{~mm}$

Side- $\mathrm{a}=97,98$

$x=72,72$ 
$\mathrm{n}=0,0$

$\mathrm{h}=.72, .72$

$\mathrm{R}=370.73 \mathrm{~mm}$

Average Radius $=407.79 \mathrm{~mm}$

After finalizing the convex Radius of the mirror, we performed iterations on the given mirror to finalize its length. The original mirror was $170 \mathrm{~mm}$ in length and $130 \mathrm{~mm}$ in height. The new mirror required a slightly higher length as compared to the old mirror, to cover the full blind spot region. We tested lengths ranging from $180 \mathrm{~mm}$ to $230 \mathrm{~mm}$ and found the $230 \mathrm{~mm}$ length to be sufficient to cover the blind spot region. This meant a $60 \mathrm{~mm}$ increase in the length of the side-view mirror, which should be accommodated in the new side-view mirror casing on the inside as the mirror casing projection outside cannot be increased due to strength reasons. According to the Automotive Research Association of India, the original Toyota Etios Liva mirror lies in Class IV and Class V Category as its average Radius of curvature is $571.94 \mathrm{~mm}$, in which the Radius of curvature has to be more than $400 \mathrm{~mm}$. The new mirror which eliminates the blind spot due to B pillars has an average Radius of curvature of $426.32 \mathrm{~mm}$, which is greater than $400 \mathrm{~mm}$, hence it will also lie in the same category. This means that the new mirror is street-legal in India. We disassembled the side view mirror from the vehicle by first removing the plastic door cover. That was only possible by removing a screw from the door lock panel, detaching 4 hooks, and disconnecting the power window mechanism. Then using a $10 \mathrm{~mm}$ spanner and ratchet the 3 side view mirror bolts were removed. Figure 4 shows the wind tunnel used for testing the flow over the mirror.

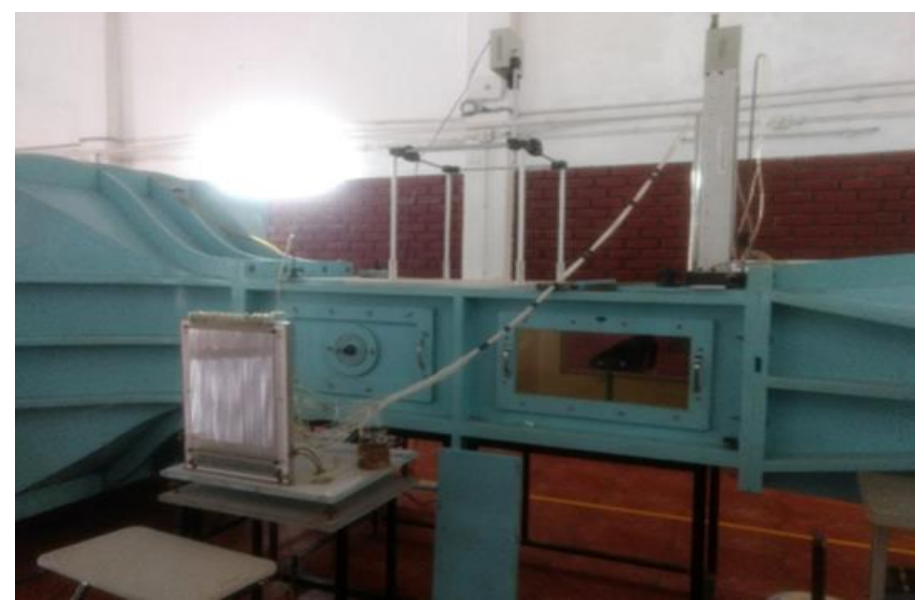

Fig. 4. Test section of the wind tunnel used for testing

In this type of method, series of 'pitot tubes' arranged at a specific distance from each other, also known as a 'Pitot Rake' is made use of. The momentum theory is used to calculate drag in this method. Each Pitot tube will calculate the pressure on the surface of the mirror. Thus, the velocity of each layer of the stream is calculated, and the coefficient of drag is obtained by substituting the drag equation. The number of Pressure ports in rake $=30$ and rake length $=100 \mathrm{~mm}$.

The procedure of the experiment-Analyse the flow over the side view mirror (Figure 5), connect the Pitot tube rake behind the model, connect nanotubes from rake to the multi-manometer, take the initial multi-manometer reading, turn on the power unit, and set RPM $(400,500,600$, and 700$)$, note down the manometer reading can be seen in Table 3, change the RPM and repeat the last 2 steps and calculate $C_{d}$ by substituting the readings in the momentum equation. 


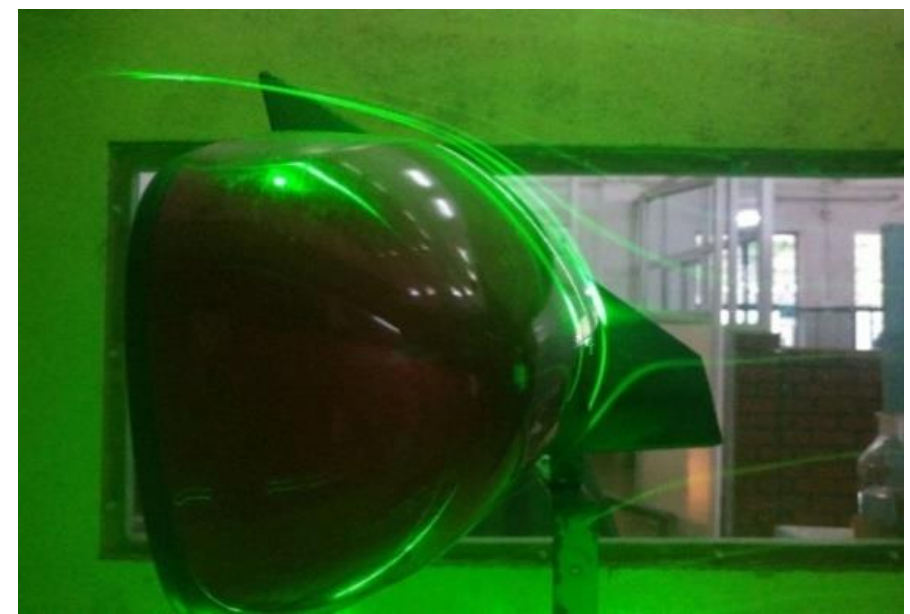

Fig. 5. Flow visualization over the side view mirror using smoke and laser apparatus

Table 3

Data collection carried out to estimate the blind spot

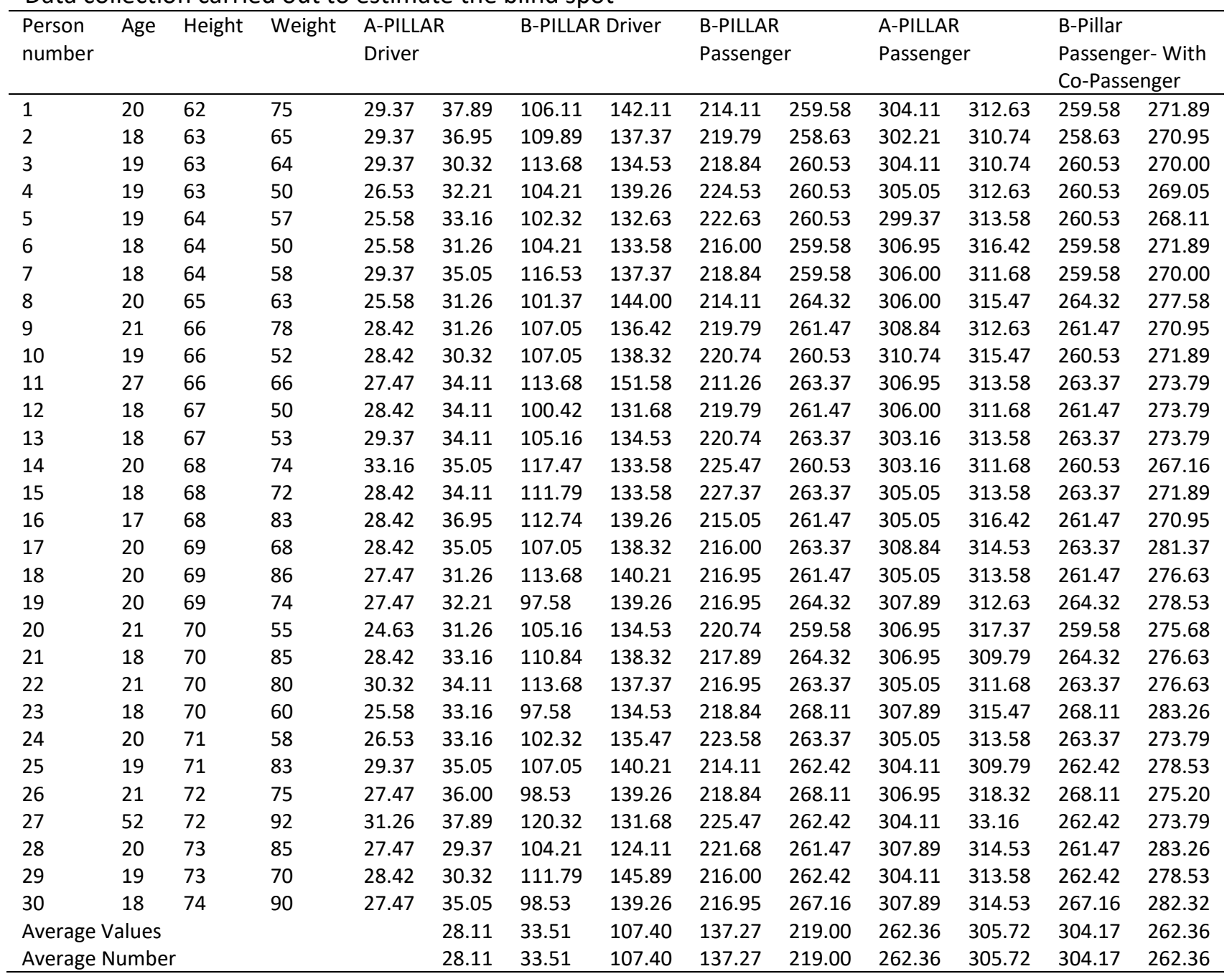


$C_{d}=\frac{F_{d}}{\frac{A \rho V^{2}}{2}}$

where $F_{D}$ is the drag force, $C_{d}$ is the drag coefficient, $A$ is the reference area, $\rho$ is the fluid density, and $V$ is the flow velocity. For airflow, $\rho=1.225 \mathrm{~kg} / \mathrm{m}^{3}, V=11.11 \mathrm{~m} / \mathrm{s}$ and $A=0.0289 .5 \mathrm{~m}^{2}$. (Area was calculated using a graph paper by adding the number of wholes, $1 / 4$ th, and $1 / 8$ th squares and multiplying the answer by the area of one square).

To compare the drag values obtained from the wind tunnel with CFD, the side view mirror from Etios Liva is replicated on CAD using Catia. Angle and length measuring devices are made use of to ensure that the CAD model was as close to the actual mirror as possible.

The design procedure involved taking a block of $250 \mathrm{~mm} \times 144 \mathrm{~mm} \times 100 \mathrm{~mm}$, followed by use of 'Cut-Extrudes' and 'Fillets' in CATIA to give it the final shape (see Figure 6).

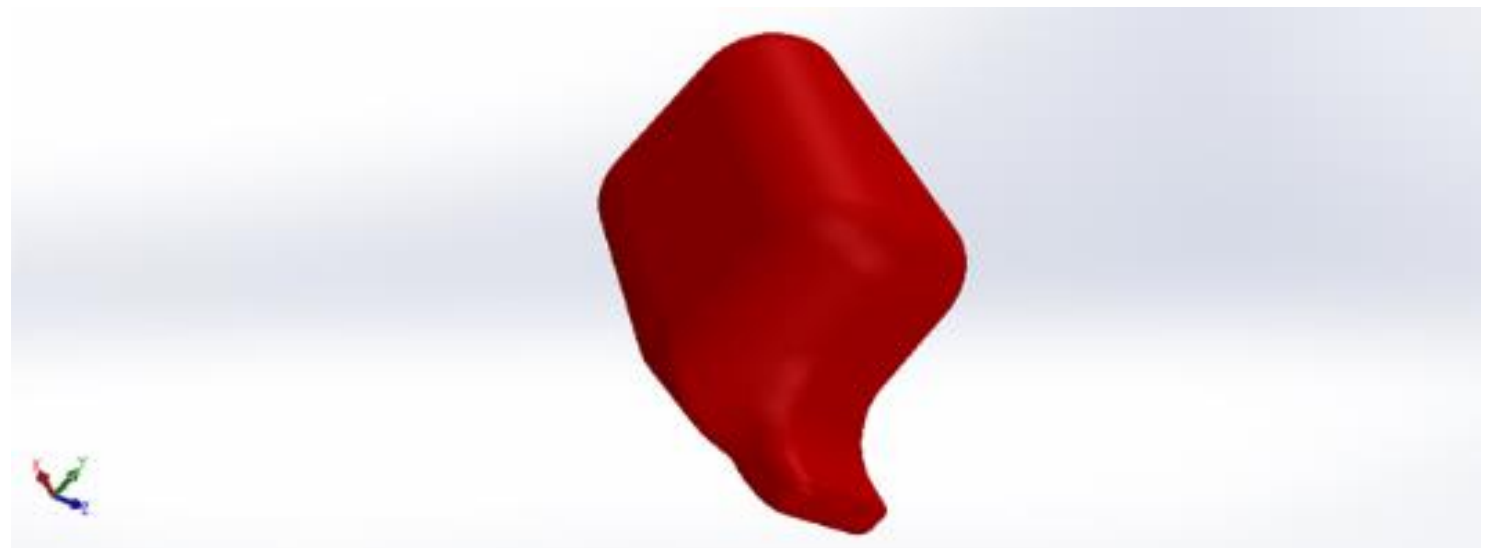

Fig. 6. Isometric view of the Toyota Side view mirror design

Mesh size is considered as $0.5 \mathrm{~mm}$ [29]. For the CFD analysis, the air flow is considered as laminar as the Reynolds number of the model is below 3000. The frontal area of the side view mirror is $0.02895 \mathrm{~m}^{2}$. The pressure was set to standard atmosphere value and the inlet velocity of air taken as $11.11 \mathrm{~m} / \mathrm{s}$ (40 kmph). The path lines for velocity and pressure over the side view mirror casing are shown in Figure 7.

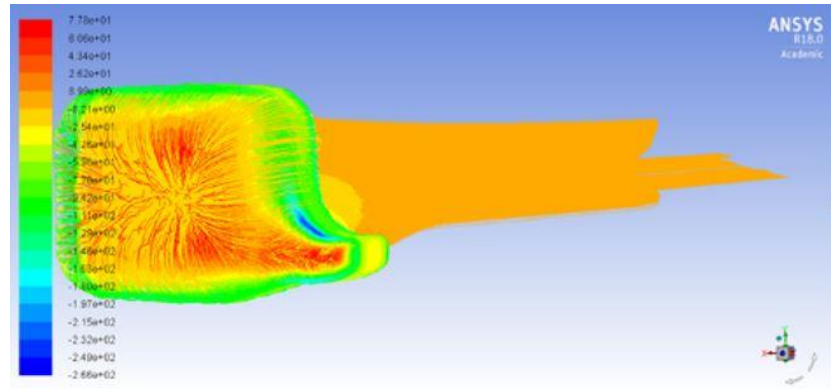

(a)

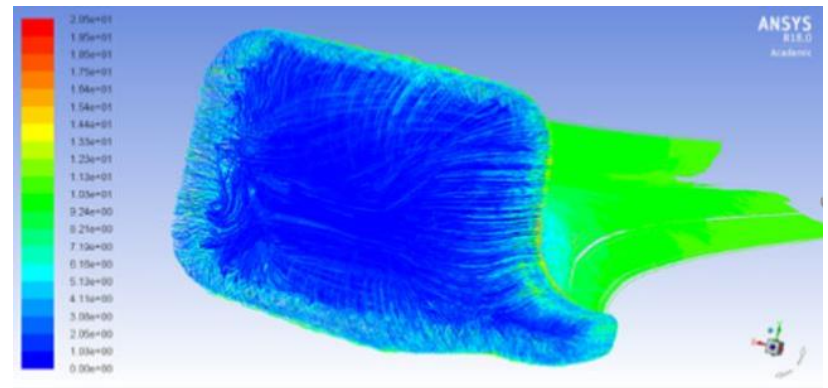

(b)

Fig. 7. Pressure and Velocity variation for the CFD analysis on the design of the original mirror

Since the new mirror is $60 \mathrm{~mm}$ more in length, a new side-view mirror casing design is made. The additional $60 \mathrm{~mm}$ is incorporated in the inner side of the side view mirror to avoid the increase in the projected length of the casing, as shown in Figure 8. The design has been done keeping in mind the shape of a solid hemisphere that has a drag coefficient of 0.42 . 


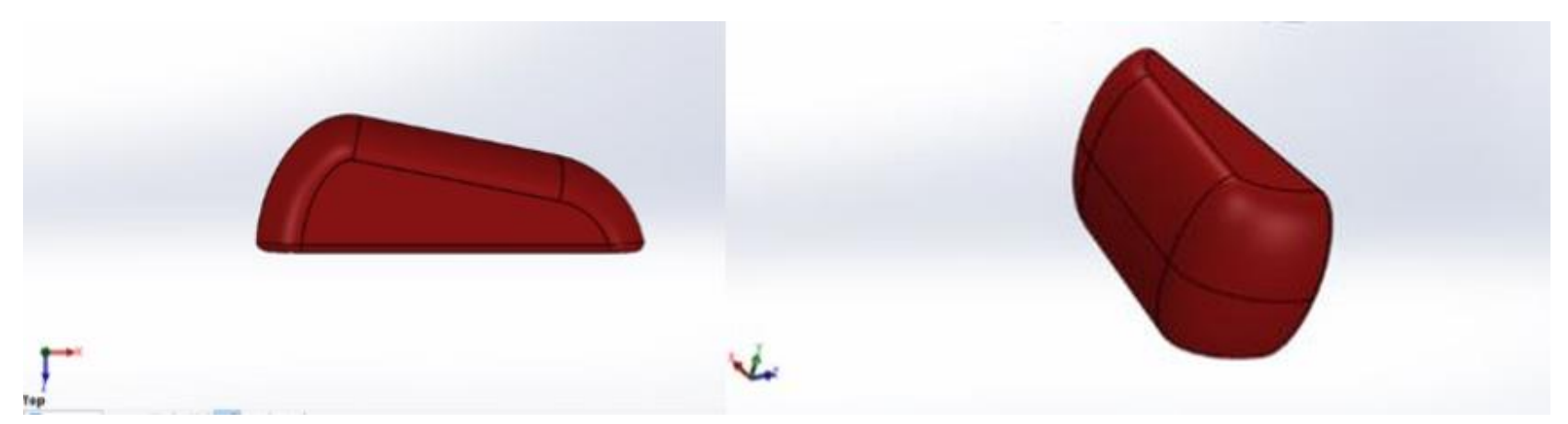

Fig. 8. Top view of the new side-view mirror design

The design is also symmetric about a plane, to reduce the manufacturing costs and to aid in the re-attachment of airflow behind the mirror, which can be seen in the simulation pictures attached. This symmetric hemispherical design resulted in a drag coefficient value of 0.449 .

The frontal area of the side view mirror is $0.035 \mathrm{~m}^{2}$. For the analysis, set the pressure to standard atmospheric value and the inlet velocity to $11.11 \mathrm{~m} / \mathrm{s}(40 \mathrm{kmph})$. The path lines for velocity and pressure over the side view mirror casing are shown in Figure 9.
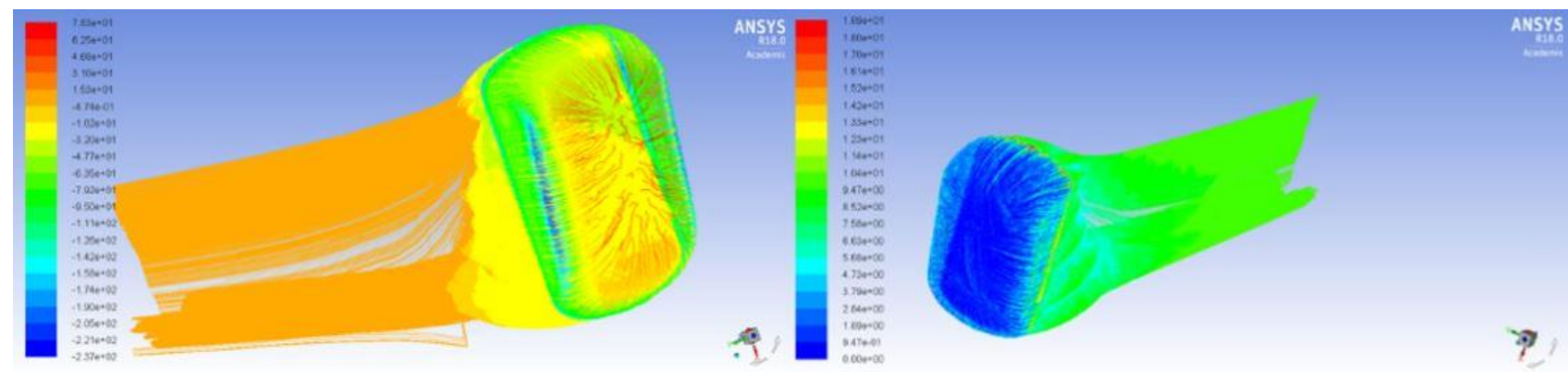

Fig. 9. Pressure and velocity variation for the CFD analysis on the design of the new mirror

\section{Result Analysis}

The work aimed to find a mirror that eliminates the blind spot regions generated in a vehicle because of the $B$ pillars and to design a new mirror casing for the same whose aerodynamic drag properties were similar to the original mirror.

The results are divided into four sections.

Blind Spot Region estimation in degree $\left({ }^{\circ}\right)$ of view measurements using the rotating pole setup of the Toyota Etios Liva Mirror.

Table 1 shows the Blindspot degrees due to each pillar.

A-Pillar Driver side $=5^{\circ} 30^{\prime}$

A-Pillar Passenger side $=1^{\circ} 53^{\prime}$

B Pillar Driver-side $=40^{\circ} 53^{\prime}$

B Pillar Passenger side $=57^{\circ} 37^{\prime}$

The total angle of the blind Spot region is $105^{\circ} 53^{\prime}$ out of the available $360^{\circ}$. This means that more than one-fourth of the driver's view from the driver's seat is blocked. This could lead to major accidents as the driver would be unaware of the presence of a vehicle in this region during an attempt 
to overtake or change from one lane to the other. This is a major safety concern, and measures should be taken to prevent such blockage regions in a mirror. Therefore, a mirror was used that reduces this blind spot region to its bare minimum, as discussed in the following section.

Blindspot ${ }^{\circ} \mathrm{s}$ due to the pillar;

A-Pillar Driver side $=5^{\circ} 30^{\prime}$

A-Pillar Passenger side $={ }^{\circ} 53^{\prime}$

B Pillar Driver-side $=40^{\circ} 53^{\prime}$

B Pillar Passenger side $=57^{\circ} 37^{\prime}$

The total minutes of the Blind Spot region $=105^{\circ} 53^{\prime}$ out of the available $360^{\circ}$.

The inference is that more than one-fourth of the total view from the driver's seat is blocked.

After testing various mirrors, the 5th test mirror of the radius of curvature $444.86 \mathrm{~mm} / 407.79$ $\mathrm{mm}$ was found to be the best solution.

Table 2 shows the Blindspot ${ }^{\circ} \mathrm{s}$ due to each pillar while using the new mirror.

B Pillar Driver-side $=2^{\circ}$

B Pillar Passenger side $=2^{\circ} 15^{\prime}$

It is seen that the new mirror has almost negligible blind-spot regions.

The blue circles in Figure 10 shows the blind spot region because of the B Pillars using a Toyota mirror. These regions are vast, up to $40^{\circ}$, and other cars as big as a Toyota Fortuner can easily lie in these regions and go unnoticed by the driver leading to deadly accidents and loss of life. The blue circles in Figure 11 show the blind spot region because of the B Pillars while using the modified mirror design. These regions are as small as $2^{\circ}$ and will not accommodate more than one-fourth portion of a regular-sized car. Hence, some part of the overtaking vehicle will always be visible to the driver and will have enough time and view to adjust the location or speed on the road, accordingly, tremendously reducing crashes and loss of life on the road.

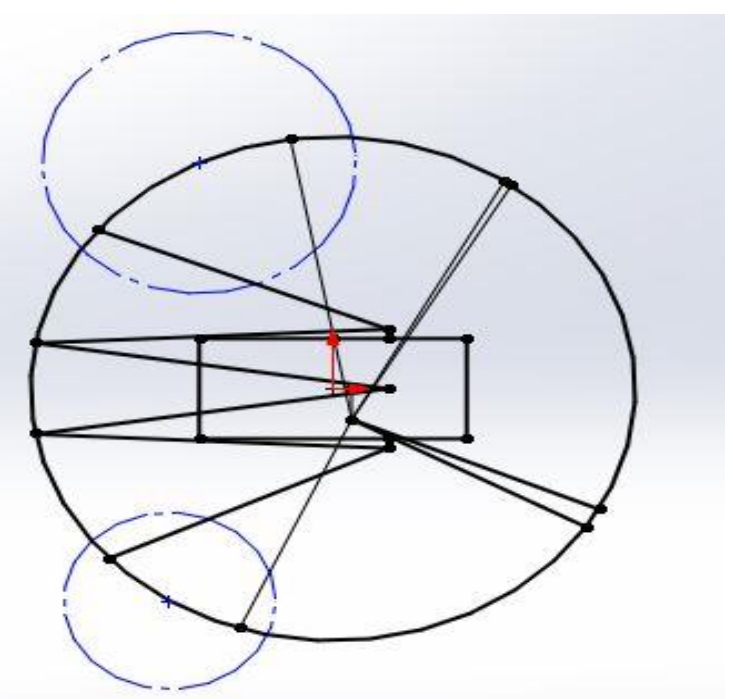

Fig. 10. Highlighted Blind spot region because of the Toyota mirror 


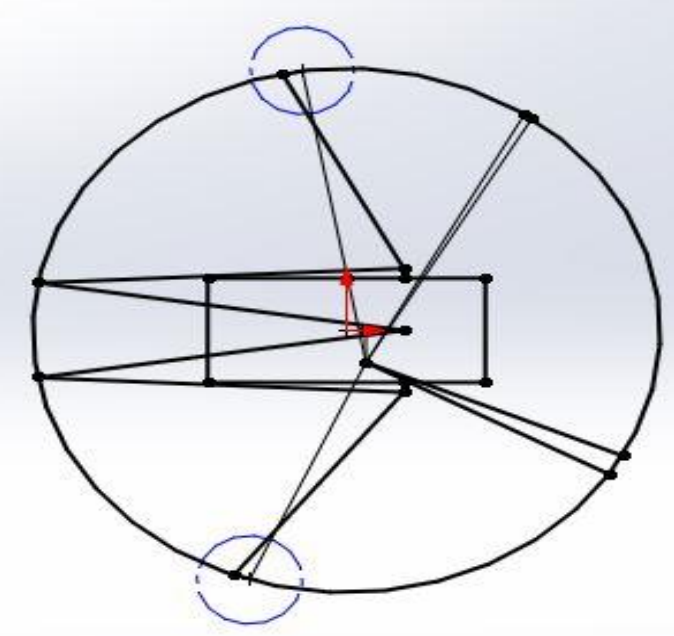

Fig. 11. Highlighted Blind spot region because of the new mirror

Since this new mirror has different dimensions than the original Toyota mirror, a new casing was designed. But this casing was supposed to have comparable aerodynamic drag properties. Therefore, we find out the drag of the original Toyota mirror casing by placing it in the wind tunnel.

Figure 12 shows the airflow around the original Toyota mirror in a wind tunnel. This was shown using Paraffin smoke and laser apparatus. We can see that the flow of air is smooth over the body of the mirror. There are a few vortex formations after the mirror body. This means that the mirror body is aerodynamically designed. The graph in Figure 13 shows the plot between the drag values and the RPM. Figure 13 shows no much change in the $C_{d}$ value with the change in RPM. This implies that the $\mathrm{Cd}$ value is consistent with speed. This value is compared with that of the CFD value.

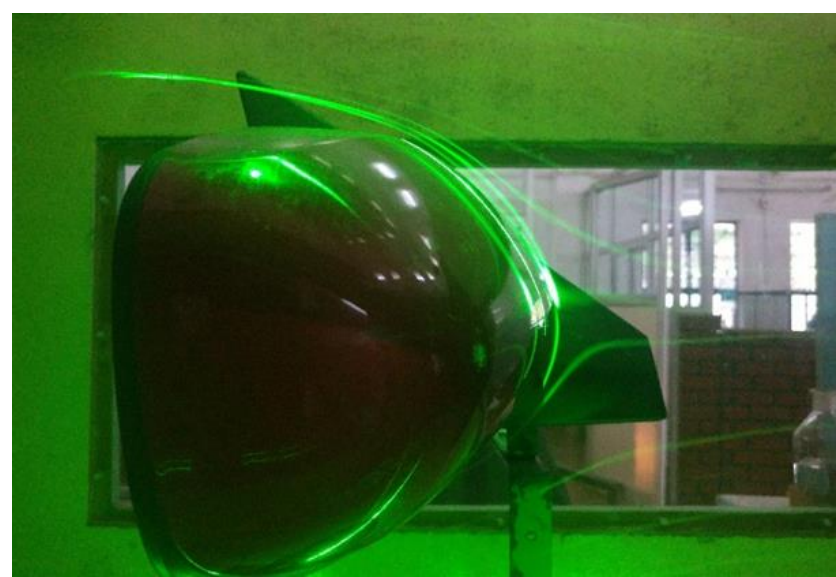

Fig. 12. Flow visualization over the side view mirror using smoke and laser apparatus 


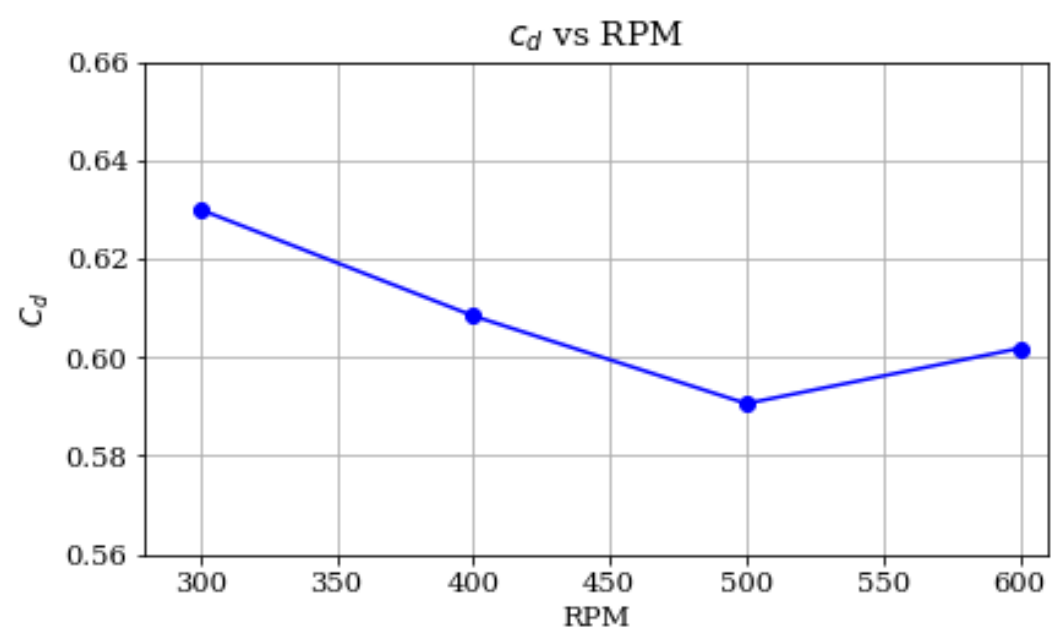

Fig. 13. Graph plot of the drag coefficient vs RPM

The drag obtained for the original curved mirror casing using wind tunnel testing was 0.609 . The CFD simulation carried out for this mirror reported a drag value of 0.634 (Table 4).

Table 4

Toyota Etios Mirror Drag Value Comparison

\begin{tabular}{lll}
\hline Drag- Wind Tunnel & Drag- CFD & Percentage Difference \\
\hline 0.609 & 0.634 & $3.94 \%$ \\
\hline
\end{tabular}

The percentage difference between the two values is found out to be $3.94 \%$, which is very less. This minor difference can be attributed to the testing conditions present. This also validates our CFD analysis procedure and hence we can run the same analysis on our new mirror casing (Table 5).

Table 5
\begin{tabular}{lll} 
Toyota Etios Mirror to New mirror Drag value Comparison (CFD) \\
\hline Drag- Mirror & Drag-New Mirror & Percentage Difference \\
\hline 0.634 & 0.449 & $29.17 \%$ \\
\hline
\end{tabular}

To verify if the new proposed mirror would comply with the aerodynamic requirement and does not result in a large drag penalty, a CFD study was also carried out. The drag obtained for the modified mirror was 0.449 which was much lesser than the original Toyota mirror. The percentage difference between the two is almost $30 \%$. Thus, the modified mirror not only avoids blind spots but is also aerodynamically superior.

\section{Conclusion}

The three main findings of the current work are - there is a total of $105^{\circ} 53^{\prime}$ blind spot region in the Toyota Etios Liva, the new rear-view mirror has almost eliminated the blind spot region due to the B pillars of a vehicle, from almost $50^{\circ}$ to merely $2^{\circ}$ on either side and the new rear-view mirror casing has a drag value which is better than the original mirror casing $(0.634$ to 0.449$)$. Thus, the proposed work not only minimizes the blind spot to its bare minimum but also is more aerodynamic than the original model. 


\section{Acknowledgments}

The authors thank the Toyota center of excellence Manipal \& Toyota Motors Pvt. Ltd, Bidadi, Bangalore for providing Toyota Etios Liva for testing purposes. The authors thank the Department of Aeronautical and Automobile Engineering, Manipal Institute of Technology, MAHE, Manipal for providing high computational facility and aerodynamics lab facility to carry out this work.

\section{References}

[1] Nyamwange, J., and D. Nyamwange. "Major innovations in transportation: Evolution of automobiles." International Journal of Humanities and Social Science 4, no. 5 (2014): 11-16.

[2] Chamberlain, Ohwojero, and E. Ede. "History of automobile past and present challenges facing automobile production in Nigeria." Journal of Research and Methods in Education 2, no. 4 (2013): 11-16. https://doi.org/10.9790/7388-0241116

[3] Sudhakar, S. "The Sales and Services offered by Showroom to Two Wheeler Buyers - An Investigation." IRACSTInternational Journal of Research in Management \& Technology (IJRMT) 6, no. 5 (2016): 26-29.

[4] Arya, Divisha. "A Study On Consumer Buying Behaviour regarding Four Wheeler." International Journal of Application or Innovation in Engineering \& Management (IJAIEM) 5, no. 10 (2016): 52-56.

[5] Petare, Purushottam A. "Consumer Buying Behavior in Four Wheeler Market With Respect To Sangli City." Online International Interdisciplinary Research Journal 3, no. 5 (2013): 359-370.

[6] Mathankumar, V., and R. Velmurugan. "Customers Preference towards Four Wheelers." Journal of Progressive Research in Social Sciences 1, no. 1 (2015): 5-11.

[7] Pawar, Sudarshan, and Sunil Naranje. "'A Study on Factors Influencing on Buying Behaviour of Customers'." Research Journal 2015 - Institute of Science, Poona College of Computer Sciences ISSN2394-1774, no. 2 (2016).

[8] Rajasekar, T., and S. Rameshkumar. "Determinants of preference towards passenger cars-The case of Madurai City in Tamilnadu." Journal of Business and Managment 17, no. 7 (2015): 84-88.

[9] Ray, Saon, and Smita Miglani. Upgrading in the Indian automobile sector: The role of lead firms. No. 360. Working Paper, 2018. https://doi.org/10.2139/ssrn.3204258

[10] Kumar, Ankit, S. K. Choudhary, and K. N. Chethan. "Commercial viability of electric vehicles in India." International Journal of Mechanical Engineering and Technology 9, no. 6 (2018): 730-745.

[11] Chethan, K. N., Laxmikant G. Keni, N. H. Padmaraj, Abhijit Dias, and Rakesh Jain. "Fabrication and Mechanical characterization of aluminium [6061] with conventionally prepared bamboocharcoal." Materials Today: Proceedings 5, no. 2 (2018): 3465-3475. https://doi.org/10.1016/i.matpr.2017.11.593

[12] Chethan, K. N., Anand Pai, N. H. Padmaraj, Ashish Singhal, and Shubham Sinha. "Effect of bamboo char and boron carbide particles on mechanical characteristics of Aluminum 6061 hybrid composites." In IOP Conference Series: Materials Science and Engineering, vol. 377, no. 1, p. 012038. IOP Publishing, 2018. https://doi.org/10.1088/1757899X/377/1/012038

[13] Hucho, Wolf, and Gino Sovran. "Aerodynamics of road vehicles." Annual Review of Fluid Mechanics 25, no. 1 (1993): 485-537. https://doi.org/10.1146/annurev.fl.25.010193.002413

[14] Hassan, S. M. Rakibul, Toukir Islam, Mohammad Ali, and Md Quamrul Islam. "Numerical study on aerodynamic drag reduction of racing cars." Procedia Engineering 90 (2014): 308-313. https://doi.org/10.1016/i.proeng.2014.11.854

[15] Ramya, P., A. Hemanth Kumar, Jaswanth Moturi, and N. Ramanaiah. "Analysis of flow over passenger cars using computational fluid dynamics." International Journal of Engineering Trends and Technology (IJETT) 29, no. 4 (2015): 170-176. https://doi.org/10.14445/22315381/IJETT-V29P232

[16] Bijlani, Bhavini, P. P. Rathod, and A. S. Sorthiya. "Experimental and Computational Drag Analysis of Sedan and Square-Back Car." International Journal of Advanced Engineering Technology 4 (2013): 63-65.

[17] Ghani, Osama Abdul. "Design optimization of aerodynamic drag at the rear of generic passenger cars using nurbs representation." PhD diss., University of Ontario Institute of Technology, 2013.

[18] Al-Obaidi, Abdulkareem Sh Mahdi, and Wesley Allen Otten. "Aerodynamic analysis of personal Vehicle side mirror." Journal of Engineering Science and Technology 13 (2018): 52-64.

[19] Sotelo, Miguel Ángel, and José Barriga. "Blind spot detection using vision for automotive applications." Journal of Zhejiang University-Science A 9, no. 10 (2008): 1369-1372. https://doi.org/10.1631/jzus.A0820111

[20] Al-Jafar, Ahmad I. S. I. "Blind spot monitoring system." U.S. Patent 8,564,425, issued October 22, 2013.

[21] Hirota, Masaki, Yasushi Nakajima, Masanori Saito, and Makoto Uchiyama. "Low-cost infrared imaging sensors for automotive applications." In Advanced Microsystems for Automotive Applications 2004, pp. 63-83. Springer, Berlin, Heidelberg, 2004. https://doi.org/10.1007/978-3-540-76989-7 6 
[22] Hannah, Arthur Andre. "Automotive blind spot safety system and method." U.S. Patent 7,517,099, issued April 14, 2009.

[23] Mohamad, Siti Khadijah. "Car Driver Asissted for Blind Spot Detection System." PhD diss., University Malaysia Pahang, 2012.

[24] Chu, K., J. Kim, K. Jo, and Myoungho Sunwoo. "Real-time path planning of autonomous vehicles for unstructured road navigation." International Journal of Automotive Technology 16, no. 4 (2015): 653-668. https://doi.org/10.1007/s12239-015-0067-5

[25] Kalburgi, Sagar, Ashwini Rathi, Mukund Narayan, Laxmikant G. Keni, Chethan K. N., and Mohammad Zuber. "Computational fluid dynamics study of cricket ball aerodynamics associated with swing." Journal of Advanced Research in Fluid Mechanics and Thermal Sciences 75, no. 2 (2020): 125-136. https://doi.org/10.37934/arfmts.75.2.125136

[26] Sabarinathan, V., Chethan K. N., Vivek Ram R., and Mahesh G. T. "Numerical Analysis and Fabrication of Battery Holder for Two Wheelers." Journal of Advanced Research in Fluid Mechanics and Thermal Sciences 78, no. 2 (2020): 114-131. https://doi.org/10.37934/arfmts.78.2.114131

[27] Basri, Mohd Salahuddin Mohd, Khairul Manami Kamarudin, Nurul Ain Maidin, and Mohd Hidayat Ab Rahman. "Aerodynamic Drag Study of Time-Trial Cycling Helmets Using CFD Analysis." Journal of Advanced Research in Fluid Mechanics and Thermal Sciences 72, no. 1 (2020): 21-31. https://doi.org/10.37934/arfmts.72.1.2131

[28] Ang, Jia Hui, Y. Yusup, Sheikh Ahmad Zaki Shaikh Salim, and Mardiana Idayu Ahmad. "A CFD Study of Flow Around an Elevator Towards Potential Kinetic Energy Harvesting." Journal of Advanced Research in Fluid Mechanics and Thermal Sciences 59, no. 1 (2019): 54-65.

[29] Ahmad, Nor Elyana, Essam Abo-Serie, and Adrian Gaylard. "Mesh optimization for ground vehicle aerodynamics." CFD Letters 2, no. 1 (2010): 54-65. 